\title{
çiência
}

\section{MISSÃO E VALORES ORGANIZACIONAIS DA ASSISTÊNCIA À SAÚDE DOS INSTITUTOS FEDERAIS DE EDUCAÇÃO, CIÊNCIA E TECNOLOGIA DO RIO GRANDE DO NORTE}

\section{Mission and organizational values of federal institutes of education, science and technology of Rio Grande do Norte's health assistance}

Janmille Valdivino da Silva • Cirurgiã-dentista do Instituto Federal de Educação, Ciência e Tecnologia do Rio Grande do Norte- IFRN. Doutoranda em Saúde Coletiva. E-mail: janmille.silva@ifrn.edu.br

Flávia Christiane de Azevedo Machado - Professora da Universidade Federal do Rio Grande do Norte. Doutora em Saúde Coletiva. E-mail: flavitamachado@yahoo.com.br

Ana Cristina Gondim Filgueira - Cirurgiã-dentista do IFRN. Mestre em Saúde Coletiva.

E-mail: ana.filgueira@ifrn.edu.br

Gerliene Maria Silva Araújo - Cirurgiã-dentista do IFRN. Mestre em Saúde Coletiva. E-mail: gerliene.araujo@ifrn.edu.br

Ideíze de Barros Medeiros • Técnica de enfermagem do IFRN. Especialista em Ambiente Organizacional, Saúde e Ergonomia. E-mail: ideize.medeiros@ifrn.edu.br

Jullyana Marion Medeiros de Oliveira • Técnica de enfermagem do do IFRN. Mestre em enfermagem.

E-mail: jullyana.oliveira@ifrn.edu.br

Sandra Maria Rodrigues Medeiros - Cirurgiã-dentista do IFRN. Mestre em Administração. E-mail: sandra.melo@ifrn.edu.br

Thiago Antônio Raulino do Nascimento • Cirurgião-dentista do do IFRN Doutorando em Ciências da Saúde.

E-mail: thiago.nascimento@ifrn.edu.br

Autora responsável pela correspondência:

Janmille Valdivino da Silva. E-mail: janmille.silva@ifrn.edu.br 


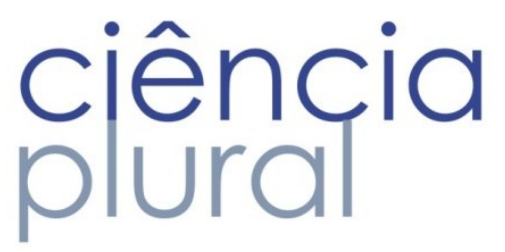

\section{RESUMO}

Introdução: Os valores de uma organização permitem predizer o seu funcionamento e o comportamento organizacional dos seus membros. As organizações se mantêm pelos seus produtos elaborados. No caso das organizações de saúde, o produto seria a atenção dispensada ao usuário. Assim, o tipo e qualidade da atenção ofertada estariam relacionados aos valores que orientam à instituição. Objetivo: Avaliar os valores organizacionais que orientam os processos de trabalho nos serviços de saúde dos diversos campi do IFRN no ano de 2014 a partir da percepção dos servidores da assistência estudantil, verificando se os valores organizacionais estão relacionados à perspectiva de trabalho em equipe, atenção pautada no cuidado e gestão participativa. Metodologia: Estudo seccional do tipo avaliação para gestão onde o Inventário de Valores Organizacionais (IVO), questionário constituído por 36 valores distribuídos em três dimensões bipolares: autonomia x conservadorismo, hierarquia x igualitarismo e domínio x harmonia, foi respondido por 41 servidores da assistência à saúde do IFRN, selecionados por conveniência, de um universo de 104 servidores. Foram realizadas as frequências absolutas e relativas e as medidas de tendência central das variáveis, bem como teste de diferença de média (t student pareado) entre as dimensões bipolares. Resultados: Dentre os valores organizacionais, o conservadorismo e a hierarquia são os mais relevantes vivenciados na vida organizacional do IFRN. O perfil axiológico do IFRN revela uma instituição mais centrada em si mesma do que na valorização dos seus membros. Conclusão: Ainda são necessários mecanismos para disseminar valores que promovam o alcance dos objetivos e metas pretendidos pela instituição e que esses sejam reconhecidos por todos que compõem a instituição.

Palavras-chave: Organização institucional. Recursos humanos. Assistência à saúde. Instituição acadêmica.

\section{ABSTRACT}

Introduction: The values of an organization allows to predict the functioning of the organization and the organizational behavior of its members. The organizations keep their elaborate products. In the case of healthcare organizations, the product would be the attention paid to the user. Thus, the type and quality of care offered would be related to the values that guide the institution. Objective: To evaluate the organizational values that guide the work processes in the health services of the various IFRN campuses in the year 2014, based on the perception of the servants of the student assistance, verifying if the organizational values are related to the perspective of teamwork, attention based on participatory care and management. Methodology: An evaluation for the management of health services Sectional Study which The Organizational Values Inventory (IVO), questionnaire consisting of 36 values distributed in three bipolar dimensions: autonomy $\mathrm{x}$ conservatism, hierarchy $\mathrm{x}$ egalitarianism and domain $\mathrm{x}$ harmony, was answered by 41 IFRN health care providers, selected by a non-probabilistic sample, from a universe of 104 health care providers. The absolute and relative frequencies and the measures of central tendency of the variables were performed, as well as the mean difference test ( $t$ student paired) between the bipolar dimensions. Results: Among these organizational values, conservatism and hierarchy are the most relevant values lived in the organizational life of the IFRN. The axiological profile of the IFRN reveals a more self-centered institution than the value of its members. Conclusion: It was observed that mechanisms are still needed to disseminate values that promote the achievement of the objectives and goals sought by the institution and that their importance is recognized by all that make up the institution.

Keywords: Institutional organization. Human Resources. Health care. Schools. 


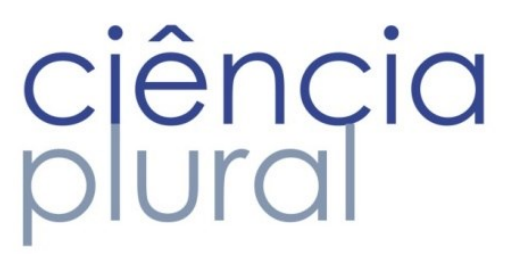

\section{INTRODUÇÃO}

As avaliações em saúde tomam como ponto de partida a produção de um conhecimento que contenha possibilidade de utilização ao assumir um conteúdo valorativo. A ideia de qualidade está presente em todos os tipos de avaliação, uma vez que têm como característica nuclear o estabelecimento de um juízo, a atribuição de um valor a alguma coisa que, quando positivo, significa ter qualidade ${ }^{1}$.

Independentemente de sua natureza e de sua constituição, as organizações se mantêm pelos seus produtos elaborados. Assim, uma organização deve primar pela qualidade de seus produtos. No caso das organizações de saúde, o produto elaborado por elas seria a atenção dispensada ao usuário. Por sua vez, a qualidade desta atenção pode ser mensurada por dimensões específicas como a segurança, a efetividade, eficiência, a centralidade no usuário, o acesso e a equidade 2 . A qualidade também estaria relacionada a significados diversos, a saber: qualidade de trabalho, de serviço, de informação, de processo, de divisão dos processos de trabalho e de pessoal ${ }^{3}$.

Contudo, em relação ao conceito de qualidade, o mais importante é defini-lo em função da missão do serviço em questão, considerando realisticamente as circunstâncias do meio em que ele está inserido. De fato, para que haja qualidade de um serviço é necessário que este disponibilize aquilo ao que se propõe para um público-específico no momento em que este público necessite, mobilizando os recursos disponíveis. Assim, o entendimento da proposição do serviço (missão) é essencial para a definição de estratégias viáveis para obtenção dos produtos esperados frente à realização de processos congruentes aos recursos existentes. Não obstante, a missão organizacional (razão da existência da instituição) juntamente com a visão (situação desejável para o futuro) e os valores organizacionais (princípios e crenças que orientam a organização, guiando o comportamento de seus membros na forma de pensar e agir) são os elementos que caracterizam a identidade institucional (personalidade e tradução do que se considera ideal para a instituição) 4 .

Quanto à funcionalidade dos valores organizacionais, estes contribuem com a consolidação da identidade social da organização, tornando-a distinta em relação às demais organizações. Além disso, permitem criar, entre os servidores, modelos mentais semelhantes, relativos ao funcionamento e à missão da organização, evitando percepções diferentes que repercutiriam no comportamento e atitudes desses servidores. Neste sentido, a importância atribuída por uma organização a certos valores pode determinar a quantidade de esforço investida por seus membros na emissão de comportamentos, bem como a persistência na execução dos mesmos. Portanto, o reconhecimento dos valores, por parte da organização, gera fatores positivos como satisfação no trabalho e o comprometimento profissional dos que a fazem ${ }^{5}$. 


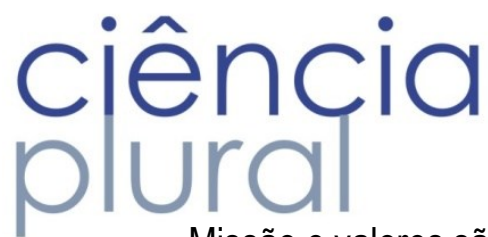

Missão e valores são pouco difundidos entre os trabalhadores das instituições de saúde, e tampouco normatizados no âmbito dos serviços de saúde. Logo, há um ponto crítico elementar para a qualidade dos serviços de saúde. Porém, há meios para identificar esses elementos, notadamente a análise bibliográfica de instrumentos normativos e demais documentos característicos de cada organização. Assim, para tanto, quanto aos serviços de saúde inseridos no Sistema Único de Saúde (SUS), deve-se avaliar a rede em que o serviço se insere, $\mathrm{a}(\mathrm{s})$ política(s) que orienta( $\mathrm{m})$ o funcionamento desta rede e o sistema no qual essas políticas são desenvolvidas.

Contudo, há outras organizações públicas não vinculadas ao Ministério da Saúde que também desenvolvem ações de saúde. Neste contexto, destacam-se os Institutos Federais de Educação, Ciência e Tecnologia (IF), instituições de ensino vinculadas ao Ministério da Educação, que disponibilizam assistência à saúde aos discentes. Portanto, se há uma difusão restrita da missão e valores dos serviços de saúde do SUS, seja entre os profissionais ou à população beneficiária, pode-se esperar que haja maiores fragilidades no âmbito dos IF. Em verdade, os IF não têm uma política de saúde institucional para orientar os profissionais de saúde sobre o que e como realizar, para quem realizar e como avaliar os resultados alcançados. Isto torna a instituição mais propensa a valores individuais para o alcance da qualidade de suas ações.

Neste contexto, este estudo se propõe a avaliar os valores organizacionais que orientam os processos de trabalho nos serviços de saúde do Instituto Federal de Educação, Ciência e Tecnologia do Rio Grande do Norte (IFRN) a partir da percepção dos servidores lotados nos serviços de saúde.

\section{METODOLOGIA}

Trata-se de um estudo observacional, descritivo, de corte seccional do tipo avaliação para a gestão, posto que seu objetivo essencial é possibilitar aprimoramentos para a gerência dos serviços de saúde pesquisados ${ }^{1}$. Participaram deste estudo 41 servidores (Coordenadores da Assistência Estudantil dos diversos campi do IFRN, profissionais de saúde e outros técnicos administrativos em educação) do universo de 104 servidores que exerciam suas funções nos serviços de saúde desse instituto no ano de 2014. Os participantes provieram de 14 dos 18 campi do IFRN que possuem serviço de saúde. Esses responderam a um questionário durante visita pré-agendada do "Grupo de Trabalho e Estudo dos Setores de Saúde" do IFRN aos campi para divulgação da política de saúde estudantil do instituto, então em construção.

Logo, constituiu-se uma amostra por conveniência, posto que a população-alvo foi composta pelos servidores presentes nos Campi nos momentos das visitas ocorridas no período de Novembro de 2014 a Janeiro de 2015.

Utilizou-se, para coleta de dados, o questionário validado por Tamayo, Mendes e Paz (2000)6 denominado Inventário de Valores Organizacionais (IVO). O IVO permite verificar a importância atribuída à 


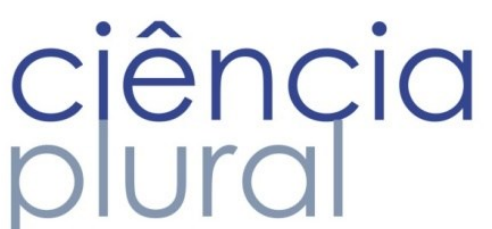

procura de inovação, de criatividade, e de independência na execução do trabalho (Autonomia); a ênfase na interdependência dos membros da organização e na obtenção de objetivos grupais (Conservadorismo); a relevância dos papéis hierárquicos na estruturação do relacionamento interpessoal e na distribuição de recursos e de poder (Hierarquia); a procura efetiva do bem-estar de todos os membros da organização e à satisfação dos clientes (Igualitarismo); a importância dada ao sucesso organizacional e à satisfação dos clientes (Domínio) e, por fim, o respeito à natureza e a procura de complementariedade organizacional (Harmonia). Este questionário conta com 36 valores organizacionais distribuídos em três dimensões bipolares, a saber: autonomia (individualismo) versus conservadorismo (coletivismo); hierarquia versus igualitarismo e domínio versus harmonia. Tais dimensões representam as alternativas de respostas das organizações. Assim, neste estudo, os valores organizacionais foram classificados em 06 tipos motivacionais definidos pelos polos dessas três dimensões, como demonstrado na Figura 1.

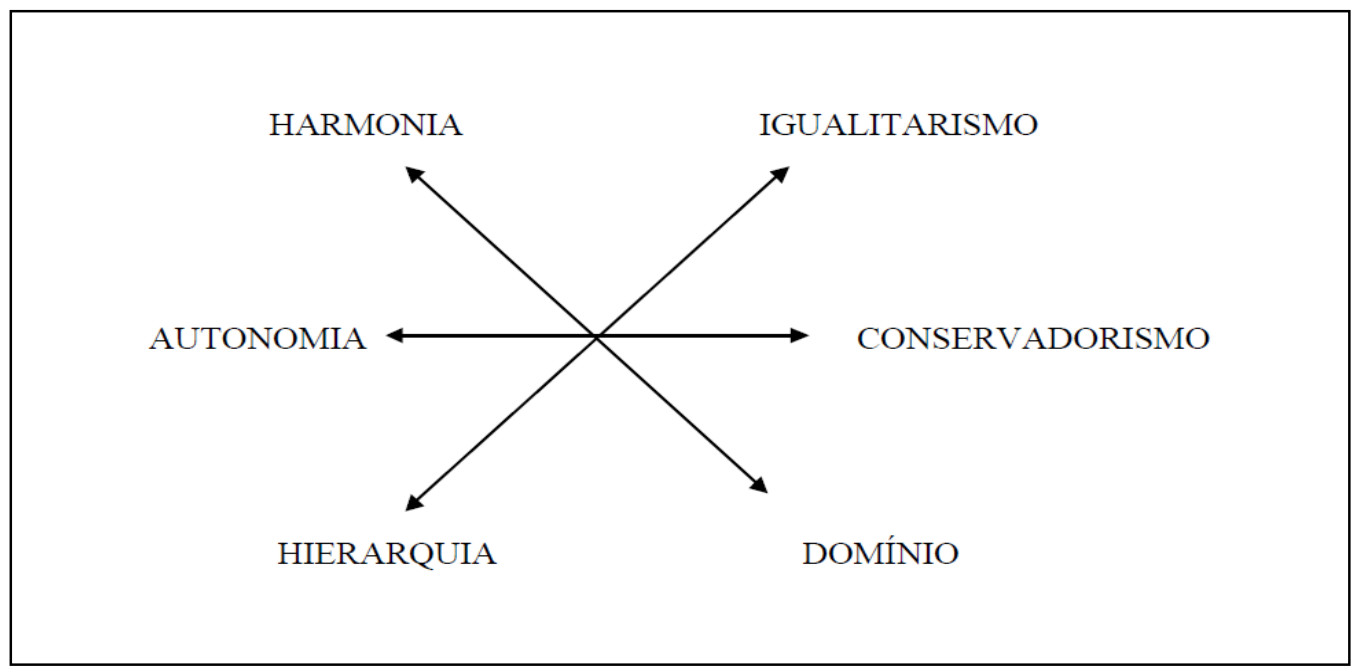

Figura 01: Estrutura teórica dos valores organizacionais. Natal-RN, 2018.

Cada um dos 36 valores organizacionais foi pontuado numa escala de Likert, de 0 a 6 , de acordo com a avaliação de quão importantes são esses valores como princípios orientadores da vida da instituição. Em seguida, foi obtido o escore final de cada tipo motivacional através do somatório dos valores escalares atribuídos pelos sujeitos a cada um dos itens que compõem o tipo motivacional dividido pelo número de itens no tipo considerado, como observado na Tabela 1. A avaliação em cada um dos tipos motivacionais foi realizada em dois níveis diferentes: dos valores reais (refere-se aos valores que, na perspectiva dos servidores, são realmente praticados na empresa e à força que eles têm na vida cotidiana da organização) e dos valores desejados (designa a prioridade ou grau de importância que os servidores gostariam que fosse dada a cada um dos valores apresentados no IVO). 


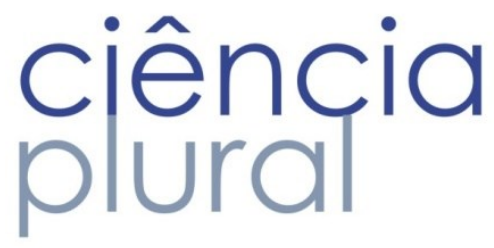

Tabela 01: Itens correspondentes a cada um dos valores motivacionais presentes no IVO. Natal-RN, 2018.

\begin{tabular}{cc}
\hline Tipos motivacionais & Itens \\
\hline Autonomia & $01,03,04,05$ \\
Conservadorismo & $02,07,08,11,16$ \\
Hierarquia & $09,10,17,18,19,20,22,24,27,28$ \\
Igualitarismo & $06,12,13,14,15,25,26$ \\
Domínio & $21,23,31,32,33,34,35,36$ \\
Harmonia & 29,30 \\
\hline
\end{tabular}

Os dados coletados foram tabulados e analisados estatisticamente com o auxílio do Programa PSPP®. Este programa é gratuito e de livre acesso, não necessitando de licença para seu uso. A análise estatística foi pertinente à pesquisa de avaliação de enfoque essencialmente descritivo. Assim, foram calculadas as frequências absolutas e relativas, bem como as medidas de tendência central das variáveis coletadas. Analisou-se a normalidade da amostra através da confecção de histograma com curva de normalidade, e obtenção de medidas de curtose, assimetria e seus respectivos erros-padrão. Em seguida, aplicou-se teste de diferença de médias (test T student) em amostra pareada para as dimensões bipolares.

\section{RESULTADOS}

O IFRN, em 2014, dispunha de 21 campi distribuídos em todo o território do Rio Grande do Norte. Todos eles, exceto os campi Educação a Distância e os de Parelhas e Lajes, então em construção, possuíam serviço de saúde. Os serviços de saúde, no total, constituíam-se de 87 profissionais da saúde (técnicos administrativos em educação) e 18 coordenadores de assistência estudantil, totalizando um número de 104 profissionais voltados para a saúde, tendo em vista que 01 profissional de saúde também exercia o papel de coordenador. Neste estudo foram avaliados 41 profissionais $(39,4 \%)$ deste universo, dentre os quais $18(43,9 \%)$ eram do sexo masculino e $23(56,1 \%)$ eram do sexo feminino. Dos 18 campi que possuíam serviço de saúde, apenas Apodi, Cidade Alta, Currais Novos e Pau dos Ferros não possuíram representantes nesta pesquisa $(22,2 \%)$.

A média de idade dos participantes foi de 34,8 anos e o tempo médio de serviço de 58,4 meses. Destes, $24,4 \%$ estavam dentro do primeiro ano de serviço na instituição e 14,6\% ocupavam cargo de chefia. Quanto à formação acadêmica, predominou às das áreas de enfermagem (40\%), medicina $(26,27 \%)$ e odontologia $(20 \%)$ e, quanto aos cargos ocupados, $30 \%$ constituíram-se de técnicos de enfermagem (Tabela 2). 
Tabela 02: Distribuição da amostra segundo formação acadêmica e cargo ocupado no IFRN. Natal-RN, 2018.

\begin{tabular}{clcc}
\hline \multicolumn{1}{c}{ VARIÁVEL } & \multicolumn{1}{c}{ CATEGORIA } & N & $\%$ \\
& Medicina & 12 & 29,3 \\
& Odontologia & 7 & 17,1 \\
\multirow{2}{*}{$\begin{array}{c}\text { Área de conhecimento } \\
\text { (N=41) }\end{array}$} & Enfermagem & 11 & 26,8 \\
& Técnico de enfermagem & 3 & 7,3 \\
& Nutrição & 2 & 4,9 \\
& Outra superior na área de humanas & 4 & 9,8 \\
& Outra superior na área exata & 1 & 2,4 \\
& Outra superior na área biociências & 1 & 2,4 \\
\hline & & & \\
& & & 29,3 \\
& Médico & 12 & 17,1 \\
& Odontólogo & 7 & 2,4 \\
Cargo & Enfermeiro & 1 & 24,4 \\
$(\mathbf{N = 4 1 )}$ & Técnico de enfermagem & 10 & 2,4 \\
& Auxiliar de enfermagem & 1 & 4,8 \\
& Nutricionista & 2 & 2,4 \\
& Psicólogo & 1 & 4,8 \\
& Auxiliar administrativo & 2 & 4,8 \\
& Assistente administrativo & 2 & 2,4 \\
& Docente & 1 & 4,8 \\
\hline
\end{tabular}

Em relação aos valores organizacionais, segundo a percepção dos servidores, o conservadorismo e a hierarquia foram os mais relevantes valores vivenciados na vida organizacional do IFRN, em detrimento do igualitarismo e harmonia que obtiveram as menores médias. Nota-se que esta percepção é uniforme entre os profissionais pesquisados como indicam os baixos desvios-padrão na Tabela 3. Ainda segundo esses servidores, o perfil axiológico do IFRN revelou uma instituição mais centrada em si mesma do que na valorização dos seus membros.

Ao pensar nos valores desejados, tais profissionais expressaram uma relevância quase equivalente a todos os valores organizacionais listados no IVO, sendo o menos prioritário neste ambiente de trabalho o domínio (Tabela 3). Essa constatação revela a necessidade de ser dada maior importância, por parte da instituição, aos valores organizacionais relacionados à satisfação dos servidores. 


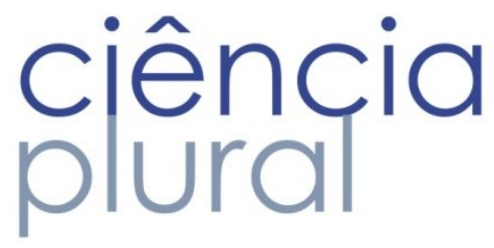

Tabela 03: Distribuição da amostra segundo formação acadêmica e cargo ocupado no IFRN. Natal-RN, 2018.

\begin{tabular}{|l|c|c|c|c|c|c|}
\hline & \multicolumn{3}{|c}{ VALORES REAIS } & \multicolumn{3}{c|}{ VALORES DESEJADOS } \\
\hline & $\boldsymbol{n}$ & Média & Desvio-padrão & $\boldsymbol{n}$ & Média & Desvio-padrão \\
\hline Autonomia & 41 & 4,10 & 1,03 & 39 & 5,58 & 0,53 \\
\hline Conservadorismo & 41 & 4,48 & 1,00 & 39 & 5,69 & 0,58 \\
\hline Hierarquia & 41 & 4,46 & 0,94 & 41 & 5,39 & 0,62 \\
\hline Igualitarismo & 40 & 3,74 & 1,19 & 40 & 5,59 & 0,54 \\
\hline Domínio & 38 & 4,16 & 1,00 & 39 & 5,16 & 0,75 \\
\hline Harmonia & 41 & 3,61 & 1,43 & 41 & 5,55 & 0,94 \\
\hline
\end{tabular}

Ao confrontarem-se os pólos axiológicos, notou-se que houve diferença estatisticamente significante entre a média nas três dimensões: conservadorismo $x$ autonomia $(p=0,01)$, hierarquia $x$ igualitarismo $(p<0,001)$ e domínio $x$ harmonia $(p<0,001)$, predominando assim o conservadorismo, hierarquia e domínio. Este achado demonstra que, na percepção dos servidores da saúde, a vida organizacional no IFRN está pautada fortemente por valores coletivos da instituição.

\section{DISCUSSÃO}

Os valores orientam a vida organizacional, o comportamento de gestores e empregados, sustentam as atitudes, motivam para a obtenção de metas e objetivos, determinam as formas de julgar e avaliar comportamentos e eventos organizacionais, influenciam o clima da organização e a tomada de decisões organizacionais ${ }^{5}$. Portanto, o conhecimento dos valores de uma organização permite predizer 0 funcionamento da mesma e o comportamento organizacional dos seus membros.

A classificação de uma organização nas seis dimensões revela as prioridades axiológicas da organização, sua base motivacional predominante e a percepção dos trabalhadores dessas prioridades 5 . Tal fato define a relação dos servidores com a organização e o seu comportamento cotidiano em função da representação cognitiva que se tem da organização. Destaca-se que os valores fazem parte de uma dialética de manutenção e de transformação dos comportamentos humanos pela socialização e aprendizagem permanentes, sendo, por isso, valiosos para as instituições que desejam modelar comportamentos em função de seus interesses ${ }^{3}$.

O IFRN, como toda organização, possui sua vida institucional pautada em valores. Estes, por sua vez, são percebidos por seus servidores, apreendidos e refletidos nos seus processos de trabalho cotidianos. Neste estudo, notou-se que os servidores pesquisados possuíam propriedade para avaliar tais valores. Eles possuíam um tempo médio de trabalho considerável (mais de 03 anos), portanto estavam aproximados da realidade organizacional e distribuídos nos mais diversos campi da instituição. 


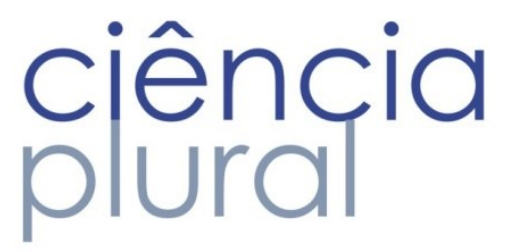

Assim, possuíam olhares diferenciados tendo em vista que a diferença regional da localização dos campi interfere na dinâmica da escola; possuíam formações acadêmicas e cargos diferenciados, o que proporciona percepções distintas dos valores organizacionais; e alguns ocupavam cargos de chefia, os quais estão bem aproximados das regras e das normatizações que regem o dia-a-dia desta organização.

Considerando os resultados encontrados pela percepção dos servidores, referentes ao construto de valores organizacionais, verifica-se que o IFRN ainda não representa uma organização ideal, mediante a ausência de isonomia entre os 06 tipos motivacionais6. Assim como não representa uma instituição ideal na concepção de tais profissionais, avaliando as diferenças obtidas entre os valores reais e aqueles desejados dos tipos motivacionais. Neste sentido, cabe salientar que qualquer organização não conseguirá atingir suas metas e eficiência sem atender às metas fundamentais das pessoas que a compõem. Dessa forma, as metas da organização devem levar em conta as percepções dos valores desejáveis por seus membros ${ }^{7}$.

Os valores organizacionais são importantes instrumentos para entender a cultura organizacional. A cultura de uma organização sustenta o processo de socializações por meio do sistema de valores, sendo tais valores vivenciados como uma experiência subjetiva compartilhada, que cria nas organizações a possibilidade de simbolização e mediação das necessidades individuais e organizacionais. Portanto, os valores têm um papel tanto de atender aos objetivos organizacionais quanto de atender às necessidades dos indivíduos ${ }^{8}$. Sua função é múltipla, mas em síntese tem o intuito de criar condições favoráveis para a emergência e o desenvolvimento do bem-estar da organização e do trabalhador?

Diante dos resultados obtidos, observa-se que o IFRN apresenta um funcionamento baseado nos pólos da conservação, hierarquia e domínio. Isso pode significar um funcionamento organizacional mais voltado para manutenção do status quo, das tradições, da ordem, disciplina, obediência à autoridade, a satisfação do público-alvo, preocupação com o mercado e com o sucesso organizacional. Organizações que enfatizam o valor do conservadorismo são aquelas que valorizam os interesses do grupo, sendo 0 interesse do indivíduo considerado como igual ao do grupo. Portanto, o IFRN enfatiza a manutenção do status atual, de instituição de ensino de excelência em qualidade, impedindo comportamentos que possam desestabilizar a vida organizacional, que venham a infringir suas normas e tradições ${ }^{9}$.

Tamayo $(2006)^{7}$ relata que o conservadorismo se caracteriza como um preditor positivo do comprometimento afetivo de membros da organização, bem como a hierarquia. Isso porque as organizações que atribuem maior importância a estes valores suscitam experiências mais reconfortantes 


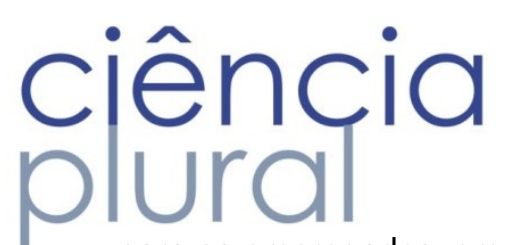

para os empregados, em virtude dos mesmos perceberem que nessas organizações as regras são mais definidas, além de haver 0 respeito às normas e maior estabilidade. Com isso, eles tenderiam a desenvolver mais vínculos afetivos com a mesma. Entretanto, este vínculo afetivo provavelmente estaria no nível da aquiescência (o profissional consente às normas da instituição), diferente do nível de identificação (o profissional se identifica com as expectativas da instituição) e de internalização (as ideias da instituição são internalizadas pelos profissionais e tomadas como verdades) que gerariam vínculos afetivos mais fortes entre profissionais e instituição ${ }^{10}$, além de estimular o pensamento crítico com base nos valores institucionais.

Entretanto, ao considerar o trabalho em saúde como uma práxis, o que torna evidente a necessidade de adaptar, por vezes, regras, condutas e protocolos à demanda vigente ${ }^{11}$, percebe-se a necessidade de maior abertura institucional do IFRN à autonomia profissional. Em verdade, as organizações que privilegiam a autonomia creem na capacidade de realização dos seus trabalhadores de forma autônoma, buscando seus próprios interesses e metas em harmonia com as metas e normas organizacionais. Portanto, enfatizam a promoção e a proteção da independência de ideias e estimulam a criatividade e a inovação7,8,9. Esta é uma característica fundamental para os serviços de saúde, considerando que seus usuários não são iguais - biológica, psicológica e culturalmente - necessitando, assim, de um olhar diferenciado na prestação da atenção à saúde, o que demanda autonomia por parte dos profissionais para análise da situação e escolha de melhores estratégias para soluções dos problemas de saúde.

Embora os IF não sejam, em essência, organizações de saúde, há a necessidade de compreender os fatores envolvidos no trabalho em saúde, já que seus serviços de saúde estão relacionados à missão do IF, ou seja, ao processo de formação educacional e cidadã dos discentes ${ }^{12}$. Neste sentido, o Projeto Político Pedagógico do IFRN descreve que, para garantir as condições básicas necessárias à concretização da educação de qualidade, são imprescindíveis a formação e a manutenção de uma equipe de trabalho interdisciplinar de profissionais de saúde e educação no âmbito da assistência estudantil. Portanto, há a compreensão de que os problemas de saúde afetam diretamente a permanência e o desempenho acadêmico dos estudantes na escola.

Contudo, essa inter-relação entre saúde e educação, apesar de presente nos documentos organizacionais, não é vivenciada no ambiente institucional. Como percebido pelos servidores da saúde, a harmonia não é um pólo axiológico privilegiado pela instituição. Logo, a complementariedade entre os setores da instituição para o alcance da missão organizacional estaria comprometida. Isto se deve, provavelmente, à ausência de mecanismos de disseminação acerca da missão do IFRN e dos valores a serem cultivados pelos profissionais da instituição de modo a garantir um ambiente favorável à sua efetivação. $O$ processo de interiorização e expansão dos institutos na última década, bem como o aumento 


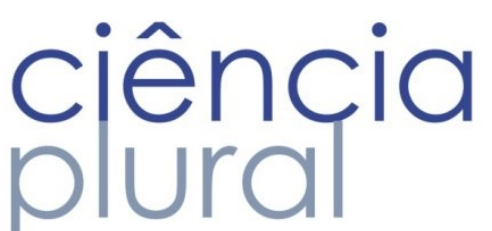

expressivo e rápido do seu quantitativo de servidores, talvez tenha suscitado essa fragilidade quanto à compreensão e internalização dos valores organizacionais por seus novos servidores. Percebe-se, dessa forma, que esta situação não se refere exclusivamente aos setores de saúde, mas é compartilhada por todos os demais setores.

Destaca-se, ainda, que o serviço em saúde dos IF, notadamente, deve ser desenvolvido na perspectiva do trabalho em equipe e da gestão participativa, seja para a integralidade do cuidado em saúde, ou seja, para a formação humana integral, função social da instituição e objetivo comum de todos os seus profissionais ${ }^{12}$. Sabe-se que cada profissional possui uma responsabilidade diferenciada para 0 alcance do objetivo da instituição, mas esta divisão de tarefas não pode perder a perspectiva do objetivo final3. Portanto, para concretização da missão do instituto, o princípio da harmonia em detrimento do domínio deveria ser mais amplamente vivenciado pelos servidores na instituição.

Deveras, no ambiente profissional também se busca satisfação. Essa é uma característica natural de qualquer ser humano. Executar um trabalho adequado quando se está desmotivado e insatisfeito é tarefa difícil. É a motivação que encoraja as pessoas a fazerem qualquer atividade, e de forma satisfatória. Motivar os empregados para alcançar altos níveis de satisfação, desempenho e produtividade constitui 0 ponto central da Psicologia do Trabalho ${ }^{13}$. Neste sentido, vale ressaltar que os servidores dos institutos federais, enquanto servidores públicos, teriam suas necessidades fisiológicas e de segurança - segundo Teoria da Hierarquia das Necessidades - garantidas. Logo, o que os motivaria para o trabalho seria a garantia de outros níveis de necessidades como as necessidades sociais (socialização e identificação com o trabalho e seu grupo) e necessidades de estima (reconhecimento e valorização do seu trabalho).

Nesta perspectiva, é primordial que uma instituição que preza pelo padrão de qualidade do trabalho oferecido leve em consideração a autonomia do profissional, explore sua criatividade e capacidade de inovação. Além disso, deve respeitar sua independência e promover a liberdade para tomadas de decisões em momentos estratégicos para que haja crescimento e evolução dos profissionais e, consequentemente, da organização. Como observado por Kwasnicka (2003) ${ }^{14}$, o trabalho que enfatiza a criatividade e o raciocínio independentes é capaz de produzir um comportamento motivado. De fato, pesquisas organizacionais mostram que uma das fontes mais frequente e poderosa de estresse ocupacional e de insatisfação no trabalho é a falta de autonomia do trabalhador no exercício das suas funções, o que gera um desinteresse por parte dos profissionais em contribuir para o bom andamento da instituição e alcance de suas metas? ${ }^{7}$.

O dueto hierarquia versus estrutura igualitária surge a partir das soluções dadas ao problema da estruturação organizacional, quando as instituições precisam definir suas funções e a relação entre suas unidades e entre seus membros. No caso do IFRN, a prerrogativa da hierarquia explicita a legitimidade 


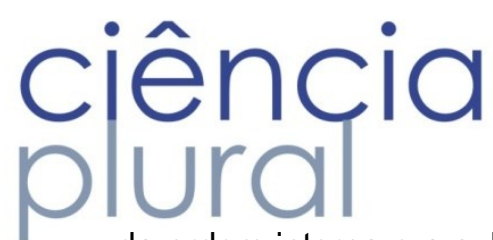

da ordem interna e a subordinação dos poderes em relação à alocação de papéis e recursos, evidente nesta instituição não só pela percepção de seus servidores, mas também pelos inúmeros níveis hierárquicos presentes no seu organograma. No entanto, é necessário entender que organizações que optam pela estrutura igualitária estariam mais preocupadas com o bem-estar de todos na organização8,9 e que esta valorização da hierarquia pode burocratizar demais os processos de trabalho, engessando as tomadas de iniciativas e procura por inovações.

Isso seria uma barreira para o processo de trabalho em saúde. Outrossim, especificamente quanto ao trabalho em saúde, mediante a tripla carga de doença, com seus determinantes e condicionantes, notase claramente a necessidade de desenvolvimento de trabalho intersetorial com a coparticipação igualitária de diversos atores, inclusive para além do serviço de saúde. Logo, a fragmentação em muitos níveis hierárquicos de tomadas de decisão pode comprometer o resultado positivo não só da equipe de saúde, mas de um todo como organização.

O fator domínio, tipo de relacionamento que a instituição estabelece com o meio físico e social, expressa as tendências de a organização ser competitiva e dominar o mercado. Privilegiando o domínio, a ênfase é buscar prosperidade por meio da autoafirmação ativa para enfrentar as mudanças externas e para dominar o ambiente social e natural. Contudo, ressalta-se que o domínio inibe o comprometimento afetivo e a identificação com a organização, talvez porque neste caso o trabalhador não se percebe como participante dos resultados obtidos pela organização?.

Percebeu-se que a amostra desta pesquisa, qualitativa e quantitativamente, representou uma fragilidade para o estudo. No tocante ao tamanho da amostra, seria interessante um número maior de servidores. Quanto à qualidade, critérios de exclusão como tempo mínimo de serviço, distribuição mais homogênea de cargos e representantes de todos os campi teriam sido importantes para a avaliação. Contudo, estes fatos não invalidam os achados, considerando o inovadorismo deste tipo de pesquisa na instituição, bem como a qualidade da análise dos resultados.

\section{CONCLUSÕES}

O IFRN, em termos de prioridades axiológicas, percebidas por seus servidores da saúde, é uma organização que enfatiza em ordem decrescente o conservadorismo, hierarquia, domínio, autonomia, igualitarismo e harmonia. Importante é destacar o predomínio do conservadorismo e as diferenças entre as dimensões, surgindo como prioridades axiológicas da organização a conservação, hierarquia e domínio. 


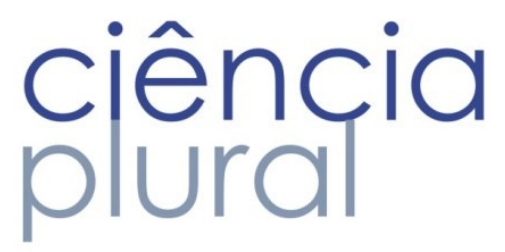

Os resultados obtidos neste estudo reforçam o quanto os valores organizacionais percebidos pelos empregados expressam as crenças sobre o que é desejável ou não para a organização. Assim, estes valores servem como padrões de comportamentos a serem seguidos no ambiente organizacional. A aceitação e ratificação dos valores organizacionais são necessárias tanto por parte dos empregados como pelos gestores, uma vez que irão orientar os comportamentos no ambiente de trabalho. Nesse sentido, a depender dos valores cultivados na organização, obtêm-se resultados positivos ou não. Assim, faz-se necessário desenvolver mecanismos para disseminar valores que promovam o alcance dos objetivos e metas pretendidos e que sua importância seja reconhecida por parte de todos que compõem a instituição. Nesse processo, é mister que a subordinação aos valores organizacionais não signifique o sacrifício dos valores pessoais, mas sim o reconhecimento da prioridade dos interesses coletivos sobre os individuais.

\section{REFERÊNCIAS}

1. Novaes HMD. Avaliação em Saúde. Revista de Saúde Pública. 2000; 34(5): 547-59.

2. Agência Nacional de Vigilância Sanitária-ANVISA. Assistência Segura: Uma Reflexão Teórica Aplicada à Prática. Brasília: ANVISA; 2013.

3. Nogueira LCL. Gerenciamento pela Qualidade Total na Saúde. Nova Lima: INDG Tecnologia e Serviços Ltda; 2008.

4. Vieira MSOC, Gomes DC. Valores organizacionais numa instituição pública de ensino no RN. Holos. 2013; 29(3): 77-89.

5. Tamayo A. Valores organizacionais: sua relação com satisfação no trabalho, cidadania organizacional e comprometimento afetivo. Revista de Administração. 1998; 33(3): 56-63.

6. Tamayo A, Mendes AM, Paz MGT. Inventário de valores organizacionais. Inventário de valores organizacionais. Estudos de Psicologia. 2000; 5(2): 289-315.

7. Tamayo A. Valores organizacionais e comprometimento afetivo. Revista de administração Mackenzie. 2006; 6(3): 192-213.

8. Mendes AM, Tamayo A. Valores organizacionais e prazer-sofrimento no trabalho. Psico-USF. 2001; 6(1): 39-46.

9. Gosendo EEM, Torres CV. Influência dos valores organizacionais sobre estilos de gerenciamento em empresas de pequeno porte. Paideia. 2010; 20(45): 29-38. 
10. Kelman HC. Interests, relationships, identities: three central issues for individuals and groups in negotiating their social environment. Annu Rev Psychol. 2006; 57(1): 1-26

11. Merhy EE, Chakkour M, Stéfano E, Stéfano ME, Santos CM, Rodríguez R A. Em busca de ferramentas analisadoras das tecnologias em saúde: a informação e o dia a dia de um serviço, interrogando e gerindo trabalho em saúde. In: Merhy EE, Onocko R (Orgs). Práxis na saúde: um desafio para o público. São Paulo: Hucitec, 1997.

12. Instituto Federal de Educação, Ciência e Tecnologia do Rio Grande do Norte-IFRN. Projeto PolíticoPedagógico do IFRN: uma construção coletiva. Natal: IFRN, 2012.

13. Peres-Ramos J. Motivação no trabalho: abordagens teóricas. Psicologia-USP. 1990; 1(2): 127-140.

14. Kwasnicka EL. Teoria geral da administração: uma síntese. $3^{a}$ ed. São Paulo: Atlas, 2003. 